\title{
Studi Alinyemen dan Perkerasan Jalan di Ruas Jalan Nasional Selat Lampa - Teluk Depih - Simpang Sekunyam, Kepulauan Natuna
}

\author{
Study of Alignment and Road Pavement in National Road of Selat \\ Lampa - Teluk Depih - Simpang Sekunyam, Natuna Islands
}

\author{
Fauzi Ahmad $^{1, \text { a) }}$, Indrasurya B. Mochtar ${ }^{2, b)}$, Soendiarto ${ }^{3, c)} \&$ K. Zulkarnain ${ }^{4, d)}$ \\ ${ }^{1)}$ Karyasiswa Magister Superspesialis Kerjasama PUPR, Departemen Teknik Sipil, Institut Teknologi \\ Sepuluh Nopember, Surabaya. \\ ${ }^{2)}$ Departemen Teknik Sipil, Institut Teknologi Sepuluh Nopember (ITS), Surabaya. \\ ${ }^{3}$ Direktorat Pembangunan Jalan, Direktorat Jenderal Bina Marga, Kementerian Pekerjaan Umum \& \\ Perumahan Rakyat. \\ ${ }^{4)}$ Balai Pelaksanaan Jalan Nasional Provinsi Kepulauan Riau, Direktorat Jenderal Bina Marga, \\ Kementerian Pekerjaan Umum \& Perumahan Rakyat.
}

Koresponden : ${ }^{a)}$ fauzimamad07@gmail.com, ${ }^{b)}$ indramochtar.mochtar@gmail.com, ${ }^{c)}$ soendiarto1970@gmail.com \& ${ }^{d)}$ mekizulkarnain@gmail.com

\begin{abstract}
ABSTRAK
Pembangunan jalan baru Selat Lampa - Teluk Depih - Simpang Sekunyam digunakan sebagai jalan utama yang menghubungkan pelabuhan dan pusat kota sehingga akan mendukung pengembangan kawasan di lokasi pelabuhan terbesar di Pulau Natuna serta upaya dalam meningkatkan pertahanan dan keamanan wilayah terluar dari isu geopolitik yang sering terjadi. Penelitian ini bertujuan untuk melakukan studi terhadap kesesuaian perencanaan geometrik jalan mengacu kepada Metode Bina Marga No. 038 T/BM/1997 ditinjau dari sisi alinyemen horizontal maupun alinyemen vertikal. Selain itu, tujuan lainnya adalah melakukan studi terhadap kebutuhan perkerasan lentur mengacu kepada MDP 2017 dan AASHTO 1993 sesuai dengan beban lalu lintas yang ada. Hasil analisis menunjukkan bahwa trase rencana terdapat 41 tikungan, 4 diantaranya belum memenuhi standar jari - jari minimum dengan kecepatan rencana $40 \mathrm{~km} /$ jam yaitu $50 \mathrm{~m}$ serta terdapat jarak antar lengkung dan landai maksimum yang masih di bawah standar. Untuk kebutuhan tebal perkerasan metode MDP 2017 didapatkan sebesar 405 mm sedangkan metode AASHTO sebesar 360 mm.
\end{abstract}

Kata Kunci : manajemen aset infrastrutkur jalan, perancangan infrastruktur, geometrik, alinyemen, perkerasan lentur

\section{PENDAHULUAN}

Pembangunan jalan baru Selat Lampa - Teluk Depih - Simpang Sekunyam di Pulau Natuna merupakan jalan yang akan mendukung pengembangan Pelabuhan Selat Lampa di Pulau Natuna. Selain itu, adanya isu geopolitik di Laut China Selatan membuat pemerintah pusat memberikan perhatian khusus di Pulau Natuna sebagai wilayah kepulauan terluar. Total panjang pembangunan jalan baru di Selat Lampa - Teluk Depih - Simpang Sekunyam pada tahun 2020 - 2022 adalah $7,10 \mathrm{~km}$. Dilihat dari prinsip manajemen aset jalan, penyelenggaraan infrastruktur jalan ini harus dirancang dengan baik agar dapat selalu berfungsi, ekonomis, efisien dan berkelanjutan (Suprayitno \& Soemitro, 2018). 
Sebenarnya terdapat jalan eksisting Selat Lampa - Simpang Sekunyam, tetapi memiliki grade lebih dari $16 \%$ sehingga tidak memungkinkan untuk dilalui kendaraan logistik dengan muatan yang berat dan hanya mampu dilalui kendaraan dengan bobot muatan kurang lebih 5 ton. Pembangunan jalan baru di Selat Lampa - Teluk Depih - Simpang Sekunyam memiliki maksud dan tujuan agar tersedianya jalan yang terpadu di kawasan dermaga Pelabuhan Selat Lampa; memperpendek waktu tempuh khusus kendaraan berat semula \pm 2 jam menjadi \pm 1 jam; serta menyediakan jalan yang berkeselamatan. Permasalahan yang ada pada lokasi pekerjaan yaitu di Sta 8+375 - 9+600 tersusun atas jenis batuan metamorf dan sedimen yaitu batuan kuarsit, rijang dan flint. Jenis morfologi pada lokasi pekerjaan berupa perbukitan tinggi berelief kasar dengan kemiringan $30^{\circ}-80^{\circ}$. Jika pembangunan tetap melalui tepi pantai, maka akan memotong bukit dengan struktur batuan beku yang menghasilkan volume galian melalui metode peledakan sangat besar. Berdasarkan latar belakang permasalahan yang ada, tujuan dari studi ini adalah melakukan tinjauan terhadap pembangunan jalan baru, untuk mengetahui kesesuaian desain yang ada berdasarkan standar Bina Marga Tata Cara Perencanaan Geometrik Jalan Antar Kota (TPGJAK) Tahun 1997 dari aspek alinyemen horizontal dan vertikal. Selain itu, dilakukan studi terhadap kebutuhan tebal perkerasan sesuai dengan proyeksi beban kendaraan yang akan melintas selama umur rencana.

\section{STUDI PUSTAKA}

\section{Klasifikasi Jalan}

Klasifikasi jalan berdasarkan Tata Cara Perencanaan Geometrik Jalan Antar Kota (TPGJAK) Tahun 1997 menurut kelas jalan dapat dilihat pada Tabel 1 dan menurut medan jalan dapat dilihat pada Tabel 2.

Tabel 1. Klasifikasi Menurut Kelas Jalan

\begin{tabular}{ccc}
\hline Fungsi & Kelas & $\begin{array}{c}\text { Muatan Sumbu Terberat } \\
\text { MST (ton) }\end{array}$ \\
\hline Arteri & I & $>10$ \\
& II & 10 \\
Kolektor & IIIA & 8 \\
& IIIA & 8 \\
\hline
\end{tabular}

Sumber : TPGJAK 1997

Tabel 2. Klasifikasi Menurut Medan Jalan

\begin{tabular}{cccc}
\hline No & Jenis Medan & Notasi & Kemiringan Medan \\
\hline 1 & Datar & D & $<3 \%$ \\
2 & Bukit & B & $3-25 \%$ \\
3 & Pegununan & G & $>25 \%$ \\
\hline \multicolumn{2}{l}{ Sumber $:$ TPGJAK 1997} & &
\end{tabular}

\section{Jalur Lalu Lintas}

Jalur adalah bagian jalan yang dipergunakan untuk lalu lintas kendaraan yang secara fisik berupa perkerasan jalan. Batas jalur lalu lintas berupa median, bahu, trotoar, pulau jalan dan separator. Jalur lalu lintas dapat terdiri atas beberapa tipe sebagai berikut : (1) 1 lajur -2 lajur - 2 arah (2/2 TB); (2) 1 lajur - 2 lajur - 1 arah (2/1 TB); (3) 2 jalur - 4 lajur - 2 arah (4/2 B); (4) 2 lajur - n lajur - 2 arah (n12 B).

TB : tidak terbagi ; $\mathrm{B}$ : terbagi ; $\mathrm{N}$ : jumlah lajur 
Lajur adalah bagian dari jalur lalu lintas yang memanjang dan dibatasi oleh marka lajur jalan, memiliki lebar yag cukup untuk dilewati kendaraan bermotor sesuai dengan kendaraan rencana. Untuk kemiringan jalur lalu lintas antara $2-3 \%$ dan bahu jalan antara $3-5 \%$. Lebar lajur ideal dapat dilihat pada Tabel 3.

Tabel 3. Lebar Lajur Ideal

\begin{tabular}{ccc}
\hline Fungsi & Kelas & $\begin{array}{c}\text { Lebar Ideal Lajur } \\
(\mathrm{m})\end{array}$ \\
\hline \multirow{2}{*}{ Arteri } & I & 3,75 \\
Kolektor & II, IIIA & 3,50 \\
Lokal & IIIA, IIIB & 3,00 \\
Sumber :TPGJAK 1997 & 3,00 \\
\hline
\end{tabular}

\section{Alinyemen Horizontal}

Alinyemen horizontal terdiri atas bagian lurus dan bagian lengkung (tikungan). Panjang jari - jari tikungan minimum $\left(\mathrm{R}_{\min }\right)$ dapat dilihat pada Tabel 4.

Tabel 4. Panjang Jari - jari Minimum $\left(\mathrm{R}_{\min }\right)$

\begin{tabular}{ccccccccc}
\hline $\begin{array}{c}\mathrm{V}_{\mathrm{R}} \\
(\mathrm{km} / \mathrm{jam})\end{array}$ & 120 & 100 & 80 & 60 & 50 & 40 & 30 & 20 \\
\hline $\mathrm{R}_{\min }(\mathrm{m})$ & 600 & 370 & 210 & 110 & 80 & 50 & 30 & 15 \\
\hline Sumber $: T P G J A K 1997$ & & & & & & &
\end{tabular}

\section{Alinyemen Vertikal}

Alinyemen vertikal terdiri atas bagian landai vertikal dan bagian lengkung vertikal. Kelandaian maksimum dapat dilihat pada Tabel 5.

Tabel 5. Kelandaian Maksimum (g)

\begin{tabular}{ccccccccc}
\hline $\begin{array}{c}\mathrm{V}_{\mathrm{R}} \\
(\mathrm{km} / \mathrm{jam})\end{array}$ & 120 & 110 & 100 & 80 & 60 & 50 & 40 & $<40$ \\
\hline $\mathrm{g}(\%)$ & 3 & 3 & 4 & 5 & 8 & 9 & 10 & 10 \\
\hline Sumber :TPGJAK 1997 & & & & & &
\end{tabular}

Panjang kritis dapat dilihat pada Tabel 6.

Tabel 6. Ketetapan Panjang Kritis

\begin{tabular}{ccccccc}
\hline Kelandaian (\%) & 5 & 6 & 7 & 8 & 9 & 10 \\
\hline Panjang Kritis (m) & 500 & 500 & 500 & 420 & 340 & 250 \\
\hline Sumber : TPGJAK 1997 & & & & &
\end{tabular}

\section{Perkerasan Lentur}

Menurut Sukirman (1999), perkerasan lentur adalah perkerasan yang menggunakan lapisan aspal sebagai bahan pengikat. Konstruksi perkerasan lentur menurut Sukirman (1999) terdiri dari lapis permukaan (surface course), lapis pondasi atas (base course), lapis pondasi bawah (subbase course) dan tanah dasar (subgrade). Dalam menghitung kebutuhan tebal perkerasan lentur dapat menggunakan metode Bina Marga MDP 2017 maupun menggunakan AASHTO 1993. 


\section{Metode Manual Desain Perkerasan Jalan (MDP) 2017}

MDP 2017 adalah salah satu metode untuk perencanaan perkerasan jalan baru yang menjelaskan faktor - faktor yang harus dipertimbangkan dalam pemilihan struktur perkerasan untuk kondisi di Indonesia yang dapat dilihat pada penjelasan berikut. Umur rencana sesuai MDP 2017 dapat dilihat pada Tabel 7.

Tabel 7. Umur Rencana Perkerasan Jalan Baru

\begin{tabular}{clc}
\hline Jenis Perkerasan & \multicolumn{1}{c}{ Elemen Perkerasan } & $\begin{array}{c}\text { Umur Rencana } \\
\text { (tahun) }\end{array}$ \\
\hline & $\begin{array}{l}\text { Lapisan aspal dan lapisan berbutir } \\
\text { Fondasi jalan }\end{array}$ & \\
Pemua perkerasan untuk daerah yang & & \\
Perkerasan lentur & $\begin{array}{l}\text { tidak dimungkinkan untuk } \text { overlay : jalan } \\
\text { perkotaaan, terowongan, underpass, } \\
\text { jembatan } \\
\text { Cement Treated Based (CTB) }\end{array}$ & 20 \\
\hline Sumber : MDP 2017 & &
\end{tabular}

Faktor pertumbuhan lalu lintas dihitung menggunakan rumus :

$R=\frac{(1+0,01 i)^{U R}-1}{0,01 i}$

Dimana :

$\mathrm{R} \quad=$ faktor pengali pertumbuhan lalu lintas kumulatif

$\mathrm{i} \quad=$ laju pertumbuhan lalu lintas tahunan $(\%)$

UR = umur rencana (tahun)

Lalu lintas lajur rencana mempertimbangkan faktor distribusi arah (DD) yang umumnya diambil 0,50 dan faktor distribusi lajur (DL) dapat dilihat pada Tabel 8.

Tabel 8. Faktor Distribusi Lajur (DL)

\begin{tabular}{cc}
\hline $\begin{array}{c}\text { Jumlah lajur } \\
\text { setiap arah }\end{array}$ & $\begin{array}{c}\text { Kendaraan niaga pada lajur desain } \\
\text { (\% terhadap populasi kendaraan niaga) }\end{array}$ \\
\hline 1 & 100 \\
2 & 80 \\
3 & 60 \\
4 & 50 \\
\hline
\end{tabular}

Beban sumbu standar kumulatif atau Cumulative Equivalent Single Axle Load (CESAL) merupakan jumlah kumulatif beban sumbu lalu lintas desain pada lajur desain selama umur rencana dihitung menggunakan rumus :

$E S A_{T H-1}=\left(\Sigma \mathrm{LHR}_{J K} \times V D F_{J K}\right) \times 365 \times \mathrm{DD} \times \mathrm{DL} \times \mathrm{R}$

Dimana :

$\mathrm{ESA}_{\mathrm{TH}-1}=$ equivalent standard axle pada tahun pertama

$\mathrm{LHR}_{\mathrm{JK}}=$ lintas harian rata - rata tiap jenis kendaraan niaga (satuan kendaraan per hari)

$\mathrm{VDF}_{\mathrm{JK}}=$ vehicle damage factor tiap jenis kendaraan niaga

$\mathrm{DD} \quad=$ faktor distribusi arah

$\mathrm{DL} \quad=$ faktor distribusi lajur

$\mathrm{R} \quad=$ faktor pengali pertumbuhan lalu lintas kumulatif 


\section{Metode AASHTO 1993}

Metode AASHTO 1993 adalah metode perhitungan yang didasarkan pada metode empiris. Dalam perhitungannya membutuhkan parameter - parameter dan rumusan yang dapat dilihat pada penjelasan berikut.

1. Persentase Sumbu Kendaraan

Dalam perhitungan ditentukan tipe dari masing - masing sumbu yaitu single axes, tandem axes dan triple axes. Kemudian ditentukan persentase masing - masing sumbu as kendaraan berdasarkan peraturan Bina Marga 1983.

2. Equivalency Axle Load Factors (EALF)

Nilai EALF membutuhkan parameter dan Indeks Permukaan Akhir (IPt) dengan nilai 2,0 ; 2,5 dan 3,0 serta parameter Structural Number (SN) yang dapat dilihat pada Appendix D.

3. Indeks Permukaan Perkerasan Lentur

Indeks permukaan terdiri dari indeks permukaan awal (IPo) dan indeks permukaaan akhir (IPt). Nilai IPo menurut AASHTO untuk perkerasan lentur adalah 4,2. Sedangkan untuk IPt dengan nilai 2,0;2,5 dan 3,0.

4. Reability

Konsep reability diaplikasikan dengan menentukan klasifikasi jalan, menentukan tingkat reability dan memilih standar deviasi untuk perkerasan lentur adalah 0,35.

5. Tanah Dasar

Modulus Resilient $\left(\mathrm{M}_{\mathrm{r}}\right)$ adalah perhitungan ketebalan perkerasan lentur dan pengganti CBR yang digunakan sebagai penunjuk daya dukung lapis perkerasan. Perhitungan Modulus Resilient $\left(\mathrm{M}_{\mathrm{r}}\right)$ menggunakan rumus :

$M_{r}=1500 \times C B R$

6. Kualitas Drainase

Pengaruh kualitas drainase dapat dilihat pada Tabel 9.

Tabel 9. Rekomendasi Nilai $m_{i}$ untuk Perkerasan Lentur

\begin{tabular}{ccccc}
\hline \multirow{2}{*}{$\begin{array}{c}\text { Kualitas } \\
\text { Drainase }\end{array}$} & \multicolumn{4}{c}{ Persen Waktu Struktur Perkerasan Dipengaruhi oleh Kadar Air } \\
\cline { 2 - 5 } & $\leq 1 \%$ & $1-5 \%$ & $5-25 \%$ & $\geq 25 \%$ \\
\hline Baik Sekali & $1,40-1,35$ & $1,35-1,30$ & $1,30-1,20$ & 1,20 \\
Baik & $1,35-1,25$ & $1,25-1,15$ & $1,15-1,00$ & 1,00 \\
Sedang & $1,25-1,15$ & $1,15-1,05$ & $1,00-0,80$ & 0,80 \\
Kurang Baik & $1,15-1,05$ & $1,05-0,80$ & $0,80-0,60$ & 0,60 \\
Tidak Baik & $1,05-0,95$ & $0,95-0,75$ & $0,75-0,40$ & 0,40 \\
\hline Sumber : AASHTO 1993
\end{tabular}

7. Perencanaan Tebal Perkerasan Lentur

Untuk tebal masing - masing lapisan menurut metode AASHTO 1993 dapat dihitung menggunakan rumus :

$\log (W 18)=Z_{r} S_{0}+9,36 \log _{10}(S N+1)-0,20+\frac{\log _{10}\left[\frac{\Delta l P}{4,-1,5}\right]}{0,40+\left[\frac{109}{(S N+1)^{5,19}}\right]}+2,32 \log _{10} M_{r}-8,07$

Keterangan dari rumus (4) dapat dilihat pada halaman selanjutnya.

Dimana :

$\mathrm{W}_{18} \quad=$ lintas ekivalen selama umur rencana

$\mathrm{SN} \quad=$ structural number/ indeks tebal perkerasan (ITP) 


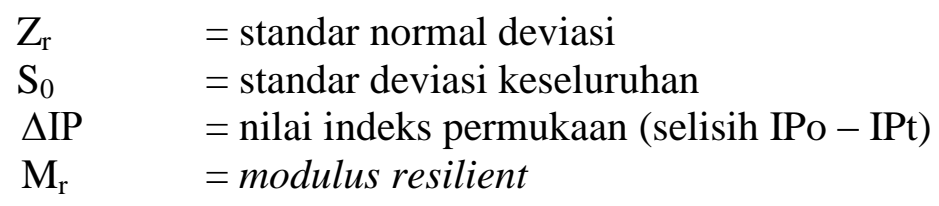

\section{METODA}

Metoda yang digunakan dalam studi ini adalah Pemodelan Geometrik Jalan dengan bantuan software Autocad Civil 3D dengan mengacu kepada persyaratan TPGJAK 1997. Untuk perhitungan kebutuhan tebal perkerasan lentur mengacu kepada MDP 2017 dan AASHTO 1993. Tahapan analisis yang dilakukan untuk menyelesaikan studi ini sebagai berikut.

\section{Studi Literatur}

Literatur yang dipelajari yaitu mengenai perencanaan geometrik jalan antar kota dan perencanaan perkerasan lentur. Selain itu dalam pemodelan juga melihat pada literatur prosedur pembuatan peta topografi dengan menggunakan software Global Mapper dan pemodelan geometrik jalan menggunakan software Autocad Civil 3D.

\section{Pengumpulan Data Lapangan}

Data yang digunakan dalam studi ini adalah data sekunder sebagai berikut.
a. Shop Drawing
b. Data Survey Lalu Lintas
c. Kajian Geologi Teknik
d. Laporan Penyelidikan Tanah

\section{Analisis Trase Jalan}

Dalam analisis trase jalan terlebih dahulu dilakukan pembuatan peta topografi dengan menggunakan data DEMNAS. Peta topografi dari DEMNAS ini hanya cocok digunakan sebagai bahan untuk studi penelitian karena tingkat akurasi yang tidak terlalu tinggi dalam menggambarkan kondisi asli di lapangan. Untuk pemodelan dilakukan dengan bantuan software Autocad Civil 3D dengan menggunakan data perencanaan dari trase jalan yang sudah direncanakan sebelumnya. Selanjutnya trase rencana tersebut akan dilakukan evaluasi dari aspek alinyemen horizontal maupun alinyemen vertikal berdasarkan standar yang ada pada TPGJAK 1997.

\section{Analisis Perkeran Lentur}

Dalam analisis perkerasan lentur menggunakan metode MDP 2017 dan AASHTO 1993. Untuk data lalu lintas yang digunakan merupakan data lalu lintas tahun 2020 yang selanjutnya dihitung proyeksi pertumbuhan pada awal umur rencana (tahun 2022). Perhitungan proyeksi pertumbuhan lalu lintas dihitung selama umur rencana 20 tahun sesuai standar umur jalan untuk jenis perkerasan lentur. Kemudian dilakukan perhitungan kebutuhan tebal perkerasan menggunakan 2 metode tersebut untuk melihat metode mana yang menghasilkan tebal perkerasan lebih efisien. 


\section{ANALISIS}

\section{Penentuan Lokasi Studi}

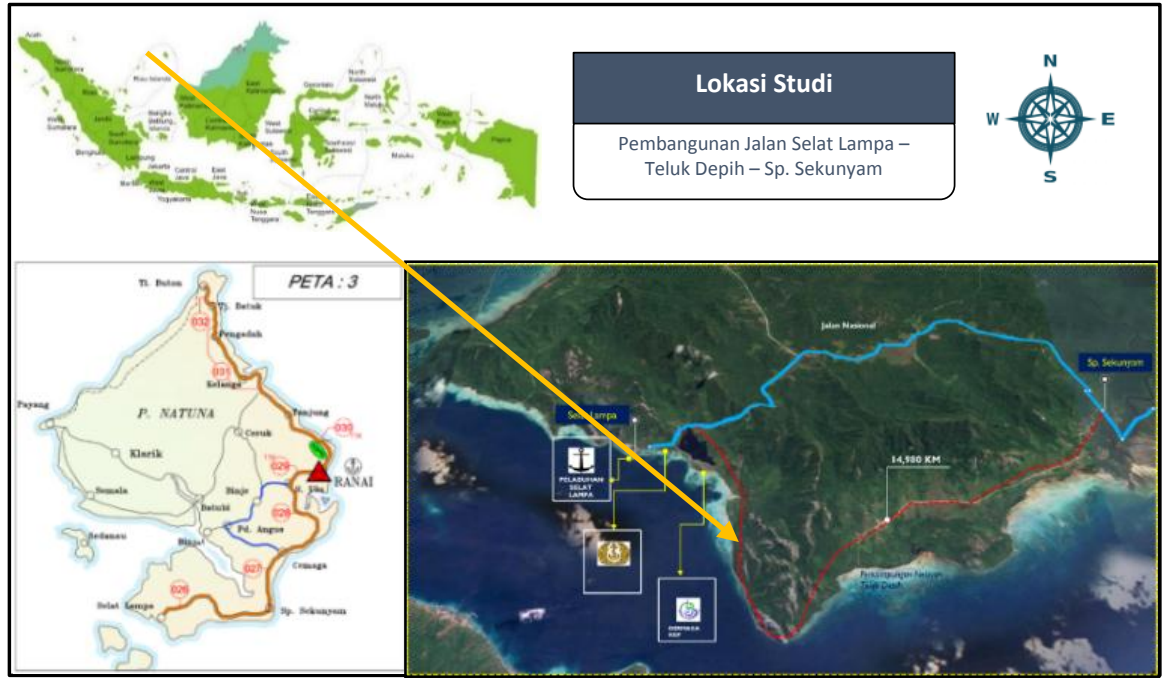

Gambar 1. Lokasi Pembangunan Jalan Selat Lampa - Teluk Depih - Simpang Sekunyam Sumber : PPK 1.4 Kepulauan Riau

\section{Geometrik Jalan}

Studi alinyemen dilakukan dengan melihat kondisi alinyemen horizontal dan alinyemen vertikal pada trase rencana yang kemudian akan dibandingkan dengan standar oleh Bina Marga yaitu TPGJAK 1997. Lokasi studi dimulai dari Sta 8+250 - 14+828 dengan peta kontur yang digunakan adalah data dari DEMNAS. Berdasarkan klasifikasi medan jalan menurut TPGJAK 1997 didapatkan kemiringan medan sebesar 21,56\% yang masuk ke dalam medan perbukitan.

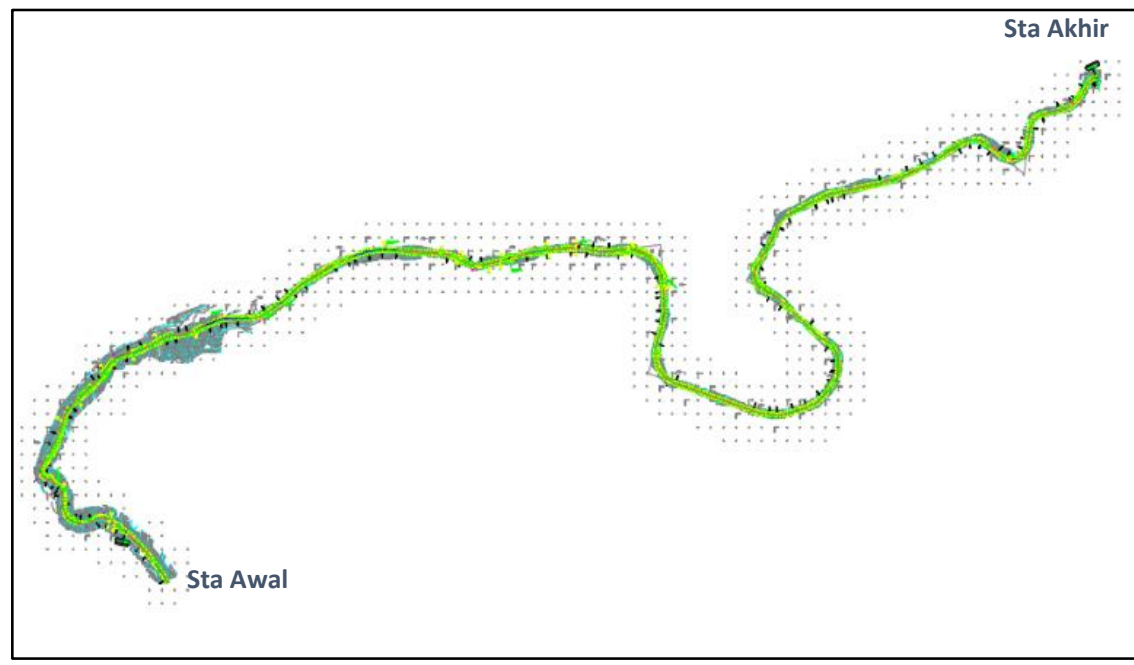

Gambar 2. Layout Lokasi Studi

Sumber : PPK 1.4 Kepulauan Riau

\section{Evaluasi Alinyemen Horizontal}

Untuk mencari jari - jari tikungan, dilakukan pemodelan sesuai dengan trase rencana pada Autocad Civil 3D. Untuk kecepatan rencana yang digunakan di trase rencana adalah 40 $\mathrm{km} / \mathrm{jam}$. Dari total 41 tikungan, terdapat 4 tikungan yang belum memenuhi standar pada aspek jari - jari tikungan (minimum 50 meter). Lalu terdapat 2 jarak lengkung yang belum 
memenuhi standar panjang daerah sisipan minimum (minimum 20 meter). Hasil evaluasi alinyemen horizontal yang belum memenuhi standar dapat dilihat pada Tabel 10.s

Tabel 10. Evaluasi Alinyemen Horizontal

\begin{tabular}{ccccccc}
\hline \multirow{2}{*}{ PI } & $\begin{array}{c}\mathrm{R}(\mathrm{m}) \\
\text { eksisting }\end{array}$ & $\begin{array}{c}\mathrm{R}(\mathrm{m}) \\
\text { minimum }\end{array}$ & Keterangan & \multicolumn{2}{c}{$\begin{array}{c}\text { Jarak Antar } \\
\text { Lengkung }(\mathrm{m})\end{array}$} & \multirow{2}{*}{ Keterangan } \\
\cline { 5 - 5 } & & & Eksisting & Standar & \\
\hline 3 & 30 & 50 & Tidak Memenuhi & 73,955 & $>20$ & Memenuhi \\
4 & 35 & 50 & Tidak Memenuhi & 30,606 & $>20$ & Memenuhi \\
5 & 20 & 50 & Tidak Memenuhi & 98,820 & $>20$ & Memenuhi \\
20 & 225 & 50 & Memenuhi & 16,695 & $>20$ & Tidak Memenuhi \\
41 & 25 & 50 & Tidak Memenuhi & 13,666 & $>20$ & Tidak Memenuhi \\
\hline
\end{tabular}

Sumber : Hasil Analisis

\section{Evaluasi Alinyemen Vertikal}

Untuk alinyemen vertikal dilihat dari aspek kelandaian maksimum pada trase rencana yang dimodelkan pada Autocad Civil 3D. Kelandaian maksimum untuk kecepatan rencana $\left(\mathrm{V}_{\mathrm{R}}\right) 40 \mathrm{~km} /$ jam sesuai TPGJAK 1997 sebesar 10\%. Dari trase rencana, terdapat 4 kelandaian yang melebihi landai maksimum yang dipersyaratkan sebesar $11,35 \% ; 10,66 \% ; 10,84 \%$ dan $10,63 \%$.

\section{Galian dan Timbunan}

Perhitungan volume galian dan timbunan dihitung dengan cara mengambil luas kedua ujung penampang. Pada pemodelan yang dilakukan dengan menggunakan referensi peta kontur dari DEMNAS didapatkan volume galian sebesar 1.949.991,45 $\mathrm{m}^{3}$ dan volume timbunan sebesar $286.712,15 \mathrm{~m}^{3}$.

\section{Perkerasan Jalan}

\section{Metode MDP 2017}

Dalam perhitungan kebutuhan tebal perkerasan lentur metode MDP 2017, terlebih dahulu dilakukan perhitungan kumulatif beban sumbu standar (CESA) dengan data sebagai berikut.

1. Umur Rencana (UR) = 20 tahun

2. Pertumbuhan Lalu Lintas (i) $\quad=6 \%$

3. Faktor Distribusi Arah (DD) $\quad=50 \%$

4. Faktor Distribusi Lajur (DL) $\quad=100 \%$

5. CBR tanah dasar $\quad=12 \%$

6. $\mathrm{R}_{(2022)}=1,124$

7. $\mathrm{R}_{(2022-2042) \quad=36,768}$

Hasil perhitungan beban sumbu standar (CESA) dapat dilihat pada Tabel 11. 
Tabel 11. Perhitungan Beban Sumbu Standar (CESA)

\begin{tabular}{|c|c|c|c|c|c|}
\hline Jenis Kendaraan & $\begin{array}{l}\text { Muatan } \\
\text { (ton) }\end{array}$ & $\begin{array}{l}\text { LHR } \\
2020 \\
\end{array}$ & $\begin{array}{l}\text { LHR } \\
2022 \\
\end{array}$ & ESA5 & $\begin{array}{c}\text { ESA }(22-42) \\
\text { Faktual } \\
\end{array}$ \\
\hline (1) & (2) & (3) & $(4)$ & (5) & (6) \\
\hline Bus Besar & 9 & 1 & 1 & 0,70 & $5.262,297$ \\
\hline Truk Ringan 2 Sumbu & 20 & 14 & 16 & 16,86 & $3.561 .672,903$ \\
\hline Truk Sedang 2 Sumbu & 25 & 47 & 53 & 43,76 & $15.514 .820,889$ \\
\hline Truk 3 Sumbu & 50 & 1 & 1 & 160,98 & $1.214 .258,905$ \\
\hline Truk Gandengan & 45 & 1 & 1 & 21,39 & $161.325,250$ \\
\hline Truk Semitrailer & 50 & 1 & 1 & 46,52 & 350.877 .194 \\
\hline & & & & CESAL5 & $20,808,217.438$ \\
\hline
\end{tabular}

Sumber : Hasil Analisis

Perhitungan Tabel 11 :

(4) $=(3) \times(1+0,06)^{2}$

(5) = diambil dari perhitungan beban sumbu standar tiap kendaraan

(6) $=(4) \times(5) \times 365 \times$ DD $\times$ DL $\times R_{(2022-2042)}$

Dari perhitungan pada Tabel 11 diperoleh nilai CESAL5 sebesar 20,808 x 106 . Untuk perancangan tebal perkerasan lentur mengacu pada Bagan Desain - 3B(1) 2020 Suplemen MDP 2017 yang dapat dilihat pada Gambar 3 dan Bagan Desain - 3C(1) 2020 Suplemen MDP 2017 untuk penyesuaian tebal lapis fondasi agregat A untuk tanah dasar CBR $\geq 6 \%$ yang dapat dilihat pada Gambar 4.

\begin{tabular}{|c|c|c|c|c|c|c|c|c|c|}
\hline & \multicolumn{9}{|c|}{ STRUKTUR PERKERASAN } \\
\hline & $F F F(1) 1^{2}$ & $\operatorname{FFF}(1) 2^{2}$ & $\operatorname{FFF}(1) 3$ & $\operatorname{FFF}(1) 4$ & $\operatorname{FFF}(1) 5$ & $\operatorname{FFF}(1) 6$ & $\operatorname{FFF}(1) 7$ & $\operatorname{FFF}(1) 8$ & $\mathrm{FFF}(1) 9$ \\
\hline & \multicolumn{4}{|c|}{$\begin{array}{l}\text { Untuk beban rencana } \leq 1 \text { juta ESA5 gunakan Struktur FFF(2) } 1 \\
\text { dari Bagan Desain } 3 B \text { (2) } 2020\end{array}$} & \multicolumn{5}{|c|}{$\begin{array}{l}\text { Opsi perkerasan dengan CTB atau perkerasan kaku mungkin lebih tepat biaya } \\
\text { tetapi mung |n tidak praktis j|k sumber daya yang diperlukan tidak tersedia }\end{array}$} \\
\hline $\begin{array}{c}\text { Beban rencana } \\
20 \text { tahun }\left(10^{6} \text { ESA5) }\right.\end{array}$ & $>1.2$ & $>2-5$ & $>5.7$ & $>7 \cdot 10$ & $>10 \cdot 20$ & $>20-30$ & $>30-50$ & $>50-100$ & $>100-200$ \\
\hline \multicolumn{6}{|c|}{ Tebal Perkerasan (mm) } & & & & \\
\hline ACWC & 40 & 40 & 40 & 40 & 40 & 40 & 40 & 40 & 40 \\
\hline$A C B C^{3}$ & 80 & 125 & 60 & 60 & 60 & 60 & so & 60 & 60 \\
\hline AC Base & - & - & 80 & 95 & 145 & 155 & 175 & 200 & 235 \\
\hline $\begin{array}{l}\text { Lapis Fondasi } \\
\text { Agregat Kelas } \mathrm{A}^{4}\end{array}$ & 300 & 300 & 300 & 300 & 300 & 300 & 300 & 300 & 300 \\
\hline
\end{tabular}

Gambar 3. Desain Perkerasan Lentur Sumber : Suplemen MDP 2017

\begin{tabular}{|c|c|c|c|c|c|c|c|c|c|}
\hline \multicolumn{10}{|c|}{$\begin{array}{c}\text { Bagan Desain - 3C (1) } 2020 \text { Penyesuaian Tebal Lapis Fondasi Agregat A Untuk Tanah Dasar CBR > 6\% } \\
\text { (Hanya Untuk Bagan Desain - 3B (1) 2020) }\end{array}$} \\
\hline & \multicolumn{9}{|c|}{ STRUKTUR PERKERASAN } \\
\hline & FFFC(1) 1 & $\mathrm{FFFC}_{(1) 2}$ & FFFC(1) 3 & FFFC(1) 4 & FFFC(1) 5 & FFFC(1) 6 & FFFC(1) 7 & FFFC(1) 8 & FFFC(1) 9 \\
\hline \multirow[t]{2}{*}{$\begin{array}{l}\text { Beban rencana } 20 \text { tahun } \\
\left(10^{6} \mathrm{ESA} 5\right)\end{array}$} & $>1-2$ & $>2-5$ & $>5.7$ & $>7-10$ & $>10-20$ & $>20-30$ & $>30-50$ & $>50-100$ & $>100-200$ \\
\hline & \multicolumn{9}{|c|}{ 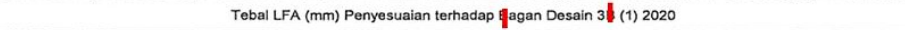 } \\
\hline Subgrade $6<C B R<7$ & 300 & 300 & 300 & 300 & 300 & 300 & 300 & 300 & 300 \\
\hline Subgrade $7 \leq C B R<10$ & 300 & 300 & 300 & 300 & 200 & 200 & 200 & 200 & 200 \\
\hline Subgrade $10 \leq C B R<15$ & 150 & 150 & 150 & 150 & 150 & 150 & 150 & 150 & 150 \\
\hline Subgrade $C B R \geq 15$ & 150 & 150 & 150 & 150 & 150 & 150 & 150 & 150 & 150 \\
\hline
\end{tabular}

Gambar 4. Penyesuaian Tebal Lapis Pondasi Agregat A untuk Tanah Dasar CBR $\geq 6 \%$ Sumber : Suplemen MDP 2017

Berdasarkan hasil perhitungan, kebutuhan tebal perkerasan yang diperlukan dengan perhitungan menggunakan metode MDP 2017 adalah sebesar 405 mm dengan lapis AC-WC 40 mm; AC-BC 60 mm; AC-Base 155 mm; LPA Kelas A 150 mm. 


\section{Metode AASHTO 1993}

Dalam perhitungan kebutuhan tebal perkerasan lentur metode AASHTO 1993 untuk ketentuan umur rencana jalan, pertumbuhan lalu lintas, nilai DD \& DL sama dengan yang digunakan pada MDP 2017. Terlebih dahulu dilakukan perhitungan persentase sumbu masing - masing kendaraan kemudian menghitung Equivalent Axle Load Factors dengan menggunakan parameter Structural Number (SN) dan IPt (Indeks Permukaan Akhir). Dalam penentuan nilai SN ini menggunakan cara trial \& error menggunakan tabel referensi dari Appendix $D$ yang ada di AASHTO 1993. Perhitungan dilakukan hingga pada perencanaan tebal lapis perkerasan lentur diperoleh nilai $\log \left(\mathrm{W}_{18}\right)$ dari perhitungan ESAL/ tahun sama dengan nilai log $\left(\mathrm{W}_{18}\right)$ menggunakan rumus AASHTO seperti pada rumus 4 di atas. Setelah dilakukan perhitungan maka diperoleh nilai $\mathrm{SN}=3,21$ dan untuk perhitungan ESAL/ tahun dapat dilihat pada Tabel 12 .

Tabel 12. Perhitungan ESAL

\begin{tabular}{|c|c|c|c|c|c|c|}
\hline Jenis Kendaraan & $\begin{array}{l}\text { Muatan } \\
\text { (ton) }\end{array}$ & $\begin{array}{c}\text { Konfigurasi } \\
\text { Sumbu }\end{array}$ & LHR 2022 & EALF & UR & $\begin{array}{l}\text { ESAL/ tahun } \\
\left(\mathrm{W}_{18}\right)\end{array}$ \\
\hline (1) & (2) & (3) & (4) & (5) & (6) & (7) \\
\hline Bus Besar & 9 & 1.2 & 1 & 0,358 & 36,79 & $2.699,317$ \\
\hline $\begin{array}{l}\text { Truk Ringan } 2 \\
\text { Sumbu }\end{array}$ & 20 & $1.2 \mathrm{~L}$ & 16 & 6,986 & 36,79 & $737.699,719$ \\
\hline $\begin{array}{l}\text { Truk Sedang } 2 \\
\text { Sumbu }\end{array}$ & 25 & $1.2 \mathrm{H}$ & 53 & 21,452 & 36,79 & $7.605 .214,125$ \\
\hline Truk 3 Sumbu & 50 & 1.22 & 1 & 50,860 & 36,79 & $383.647,257$ \\
\hline Truk Gandengan & 45 & $1.2+2.2$ & 1 & 8,277 & 36,79 & $62.434,557$ \\
\hline Truk Semitrailer & 50 & $1.2-22$ & 1 & 20,499 & 36,79 & $154.624,648$ \\
\hline \multicolumn{6}{|c|}{ Total ESAL/ tahun $\left(\mathrm{W}_{18}\right)$} & $8.946 .319,623$ \\
\hline & & & \multicolumn{3}{|c|}{$\log \left(\mathrm{W}_{18}\right)$} & 6,952 \\
\hline
\end{tabular}

Sumber : Hasil Analisis

Perhitungan :

$(7)=(4) \times(5) \times(6) \times 365 \times D D \times D L$

Dari perhitungan diperoleh nilai $\mathrm{SN}=3,21$; IPt $=2,5$ dan nilai $\log \left(\mathrm{W}_{18}\right)=6,952$. Berdasarkan hal dilakukan perhitungan menggunakan rumus 4 untuk melakukan cek terhadap nilai SN yang diperoleh sama dengan nilai $\log \log \left(\mathrm{W}_{18}\right)$ dari perhitungan ESAL/ tahun untuk masing - masing lapisan. Nilai SN masing - masing lapisan dari perhitungan rumus AASHTO adalah $\mathrm{SN}_{1}=1,38 ; \mathrm{SN}_{2}=1,61$ dan $\mathrm{SN}_{3}=3,21$. Setelah diperoleh nilai $\mathrm{SN}$ masing - masing lapisan ditentukan nilai koefisien lapis perkerasan dan koefisien kualitas drainase.

Koefisien lapis perkerasan diambil nilai $\mathrm{a}_{1}=0,44 ; \mathrm{a}_{2}=0,14$ dan $\mathrm{a}_{3}=0,11$

Koefisien kualitas drainase drainase baik dengan nilai $\mathrm{m}_{2}=1,00$ dan $\mathrm{m}_{3}=1,00$

Untuk tebal masing - masing perkerasan sebagai berikut :

$$
\begin{array}{ll}
\mathrm{D}_{1}=\mathrm{SN}_{1} / \mathrm{a}_{1} & =3,14 \text { inch } \\
\mathrm{D}_{2}=\left(\mathrm{SN}_{2}-\mathrm{SN}_{1}\right) /\left(\mathrm{a}_{2} \times \mathrm{m}_{2}\right) & =1,61 \text { inch } \\
\mathrm{D}_{3}=\left(\mathrm{SN}_{3}-\mathrm{SN}_{2}-\mathrm{SN}_{1}\right) /\left(\mathrm{a}_{3} \times \mathrm{m}_{3}\right) & =2,01 \text { inch }
\end{array}
$$

Selanjutnya dilakukan koreksi terhadap tebal minimum yang telah ditentukan untuk lapisan permukaan dan lapisan pondasi mengacu kepada Washington State Department of Transport (WSDOT) tahun 2005. Diketahui nilai ESAL/ tahun lebih dari 7.000.000 maka ditentukan tebal minimum lapisan aspal yaitu 4 inch dan batu pecah 6 inch (D2 dan D3). Untuk kebutuhan tebal perkerasan dengan menggunakan AASHTO sebagai berikut. 
Tabel 13. Kebutuhan Tebal Perkerasan Lentur Metode AASHTO 1993

\begin{tabular}{|l|c|c|c|c|c|c|c|c|}
\hline & \multicolumn{3}{|c|}{ Tebal Awal } & \multicolumn{5}{c|}{ Tebal Akhir Koreksi } \\
\cline { 1 - 4 } $\mathrm{D}_{1}$ & 3,14 & inch & 7,98 & $\mathrm{~cm}$ & 4,00 & inch & 11,00 & $\mathrm{~cm}$ \\
\hline $\mathrm{D}_{2}$ & 1,61 & inch & 4,09 & $\mathrm{~cm}$ & \multirow{2}{*}{6,00} & inch & 16,00 & $\mathrm{~cm}$ \\
\cline { 1 - 5 } $\mathrm{D}_{3}$ & 2,01 & inch & 5,11 & $\mathrm{~cm}$ & & & & \\
\hline
\end{tabular}

$\mathrm{D}_{1}$ merupakan lapis permukaan dengan tebal sebesar $11 \mathrm{~cm}$ dibagi menjadi AC-WC 4 $\mathrm{cm}$ dan AC-BC $7 \mathrm{~cm}$. $\mathrm{D}_{2}$ dan $\mathrm{D}_{3}$ merupakan lapis pondasi batu pecah (agregat kelas $\mathrm{A}$ dan kelas $\mathrm{B}$ ) dengan tebal $\mathrm{D}_{2}$ sebesar $10 \mathrm{~cm}$ dan tebal $\mathrm{D}_{3}$ sebesar $15 \mathrm{~cm}$.

\section{KESIMPULAN}

Berdasarkan hasil pengumpulan data dan analisis yang sudah dilakukan maka dapat disimpulkan sebagai berikut :

- Pada alinyemen horizontal di lokasi studi belum memenuhi standar TPGJAK 1997 karena dari 41 tikungan terdapat 4 tikungan yang tidak memenuhi radius minimum $50 \mathrm{~m}$ serta terdapat 2 jarak antar lengkung yang tidak memenuhi jarak antar lengkung minimum $20 \mathrm{~m}$.

- Pada alinyemen vertikal di lokasi studi terdapat 4 kelandaian yang melebihi landai maksimum sesuai standar TPGJAK 1997 sebesar 10\%.

- Kondisi morfologi perbukitan di lokasi studi tersusun atas tiga jenis batuan metamorf dan sedimen yaitu batuan kuarsit, rijang dan flint.

- Volume galian yang dihasilkan cukup besar, dalam pelaksanaan dikhawatirkan terdapat kesulitan dalam proses penggalian karena kondisi batuan di lokasi pekerjaan yang termasuk ke dalam batuan keras selain itu juga terdapat bahaya dari guguran dari proses penggalian batu tersebut.

- Pehitungan perkerasan lentur metode MDP 2017 cenderung lebih besar karena kebutuhan tebal perkerasan ditinjau dari bagan desain dengan nilai ESAL rentang minimum hingga maksimum sedangkan perkerasan lentur metode AASHTO 1993 penentuan tebal perkerasannya berdasarkan nilai ESAL sesuai kebutuhan.

- Kebutuhan perkerasan lentur menggunakan MDP 2017 diperoleh tebal perkerasan sebesar $405 \mathrm{~mm}$ dengan masing - masing lapisan yaitu AC-WC $40 \mathrm{~mm}$; AC-BC 60 $\mathrm{mm}$; AC-Base $155 \mathrm{~mm}$; LPA Kelas A $150 \mathrm{~mm}$.

- Kebutuhan perkerasan lentur menggunakan AASHTO diperoleh tebal perkerasan sebesar $40 \mathrm{~cm}$ dengan masing - masing lapisan yaitu AC-WC $40 \mathrm{~mm}$; AC-BC 70 mm; Agregat Kelas A 100 mm dan Agregat Kelas B 150 mm.

- Nilai tebal minimum diperoleh dari ketentuan Washington State Department of Transport (WSDOT) tahun 2005 mengenai Pavement Guide Interactive.

\section{SARAN}

Perlu dilakukan optimasi pada trase rencana di lokasi studi sebagai pembanding dari trase rencana yang sudah ada agar memenuhi standar yang dipersyaratkan dan menghasilkan alinyemen yang lebih optimum dari sisi galian dan timbunan, terutama untuk mengurangi jumlah volume galian batu yang besar karena dikhawatirkan dapat terjadi guguran batuan di masa mendatang. Pada aspek kelandaian maksimum sebaiknya dibatasi sebesar maksimum 5\% karena lokasi studi merupakan jalan penghubung dari pelabuhan menuju pusat kota sehingga kendaraan logistik dapat melintas dengan lebih aman dan nyaman. Untuk 
perencanaan desain yang akan dilaksanaan di lapangan sebaiknya menggunakan peta topografi dari hasil survei lapangan agar perencanaan yang dihasilkan dapat lebih akurat.

\section{DAFTAR PUSTAKA}

AASHTO. (1993). Officials Guide for Design of Pavement Structures. American Association of State Highway and Transportation. USA.

Agustono, Decha Julian. (2021). "Perancangan Geometrik Jalan dan Perkerasan Jalan Lentur pada Jalan Sidodadi - Sanerejo - Batas Banyuwangi di Kabupaten Jember Provinsi Jawa Timur”. Skripsi Sarjana. Institut Teknologi Sepuluh Nopember. Surabaya.

Direktorat Jenderal Bina Marga, (1997). Tata Cara Perencanaan Geometrik Jalan Antar Kota. Departemen Pekerjaaan Umum. Jakarta.

Direktorat Jenderal Bina Marga. (2017). Manual Desain Perkerasan Jalan 2017. Kementerian Pekerjaaan Umum dan Perumahan Rakyat. Jakarta.

Direktorat Jenderal Bina Marga. (2020). Suplemen Manual Desain Perkerasan Jalan (MDP) 2017. Kementerian Pekerjaan Umum dan Perumahan Rakyat. Jakarta

Febrama, Zilki Arfansya. (2018). "Perencanaan Konstruksi Perkerasan Lentur dan Perkerasan Kaku Jalan Tol Semarang - Batang dengan Metode AASHTO Ditinjau dari Segi Ekonomi”. Skripsi Sarjana. Institut Teknologi Sepuluh Nopember. Surabaya.

Gusti, Rizki. dkk. (2020). "Studi Perancangan Geometrik dan Perkerasan Lentur Jalan Ring Road Timur (JRRT) Kota Madiun”. Jurnal Teknik ITS Vol. 9, No. 1, (2020). ISSN: 2337-3539. Surabaya.

Mantiri, Cynthia Claudia, dkk. (2019). "Analisa Tebal Perkerasan Lentur Jalan Baru dengan Metode Bina Marga 2017 dibandingkan Metode AASHTO 1993”. Jurnal Sipil Statik, Vol. 7 No. 10 (1303-1316), ISSN : 2337-6732.

PerMen PU. 19/11. Peraturan Menteri Pekerjaan Umum tentang Persyaratan Teknis Jalan dan Kriteria Perencanaan Teknis Jalan. Kementerian Pekerjaan Umum. Jakarta.

PPK 1.4, Satuan Kerja Pelaksanaan Jalan Nasional Wilayah I Kepulauan Riau. (2020). Gambar Rencana Paket Pembangunan Jalan Selat Lampa - Teluk Depih - Sp. Sekunyam (Pengalihan Trase) UMYC. Kepulauan Riau.

Satuan Kerja Pelaksanaan Jalan Nasional Wilayah I Kepulauan Riau. (2020). Kajian Geologi Teknik di Jalan Nasional Selat Lampa - Sekunyam KM 8+375 - 9+600. Kepulauan Riau.

Sukirman, Silvia. (1999). Perkerasan Lentur Jalan Raya. Penerbit Nova. Bandung.

Suprayitno, H. \& Soemitro, R.A.A. (2018). "Preliminary Reflexion on Basic Principle of Infrastructure Asset Management”. Jurnal Manajemen Aset Infrastruktur \& Fasilitas, 2(1) Maret 2018.

WSDOT. (2005). Pavement Guide Interactive. Washington State Department of Transportation. USA. 